\title{
Devulcanization of Styrenebutadiene (SBR) Waste Tire by Controlled Oxidation
}

\author{
Rachel R.V.A. Rios, Manuela Gontijo, Vany P. Ferraz, Rochel M. Lago and Maria Helena Araujo* \\ Departamento de Química, ICEx, Universidade Federal de Minas Gerais, Campus-Pampulha, \\ 31270-901 Belo Horizonte-MG, Brazil
}

\begin{abstract}
Neste trabalho é descrita a desvulcanização da borracha SBR (Styrene Butadiene Rubber) via oxidação controlada com ácido nítrico. Análises por IV, RMN de ${ }^{1} \mathrm{H}$ e ${ }^{13} \mathrm{C}, \mathrm{CHN}, \mathrm{TG}, \mathrm{GPC}$ e experimentos de DTP-EM (Decomposição a Temperatura Programada -Espectrometria de Massas) sugerem que o ácido nítrico promove dois processos: (i) a desvulcanização por oxidação das pontes de enxofre e (ii) a oxidação da cadeia carbônica levando à formação de grupos $-\mathrm{COOH} \mathrm{e}-\mathrm{NO}_{2}$. Em condições mais drásticas de reação, a cadeia polimérica é fortemente oxidada e se fragmenta formando uma fração altamente oxigenada, de baixo peso molecular e solúvel em água.
\end{abstract}

This work describes the devulcanization of vulcanized SBR (Styrene Butadiene Rubber) based on controlled oxidation with nitric acid. IR, ${ }^{1} \mathrm{H}$ and ${ }^{13} \mathrm{C}-\mathrm{NMR}, \mathrm{CHN}$ elemental analyses, TG, GPC and TPD-MS (Temperature Programmed Decomposition-Mass Spectrometry) experiments suggest that nitric acid promotes two processes: (i) devulcanization by oxidation of the sulfide crosslinks and (ii) oxidation of the carbon framework leading to the formation of $-\mathrm{COOH}$ and $-\mathrm{NO}_{2}$ groups. Under aggressive conditions ( $\mathrm{HNO}_{3}$, reflux) the polymer chain is strongly oxidized and fragmented to a highly oxygenated low molecular weight fraction, which is soluble in water.

Keywords: devulcanization, $\mathrm{HNO}_{3}$, oxidation

\section{Introduction}

The disposal and reuse of waste tires remain not only a serious environmental concern but also an economical issue. Several alternatives, such as direct uses of scrap tires, combustion to produce energy, pyrolysis to produce fuels, the use of crumbles to asphalt roads and devulcanization to recycle the polymer have been extensively investigated in the last decades. Different chemical, physical and biological processes for the devulcanization of vulcanized rubber have been reported in the literature. ${ }^{1}$ For the chemical devulcanization processes an extensive variety of agents such as: sulphides, e.g. diphenyl-disulphides, mercaptans, thiophenol, phosphorus compounds, e.g. triphenylphosphine and dibutylphosphite have been used. ${ }^{2-13}$ Also, some reducing compounds have been studied for the devulcanization process, such as lithium aluminum hydride, ${ }^{14}$ phenyl lithium, ${ }^{15} \mathrm{CuCl} / \mathrm{Bu}_{3} \mathrm{~N},{ }^{16}$ alkaline metals (e.g. $\mathrm{Na}^{\circ}$ ) and $\mathrm{FeCl}_{2} /$ hydrazine. ${ }^{17}$ On the other hand, oxidative processes for the devulcanization have been scarcely investigated. One example is the use of $\mathrm{CHCl}_{3} / \mathrm{O}_{3} / \mathrm{H}_{2} \mathrm{O}_{2}$, which showed low efficiency and high cost. ${ }^{18}$

*e-mail: mharaujo@ufmg.br
Nitric acid, $\mathrm{HNO}_{3}$, is a strong oxidizing agent which is well known to react with all types of sulfur groups, ${ }^{19}$ offering the possibility to devulcanize rubber by oxidizing the sulfide crosslinks. The corrosion effect of nitric acid on rubber surface has been observed in 1985 by scanning electron microscopy. ${ }^{20}$ Also $\mathrm{HNO}_{3}$ and $30 \% \mathrm{H}_{2} \mathrm{O}_{2}$ have been used for the modification of the surface properties of rubber powder used as filler. ${ }^{21}$ However, the use of the controlled oxidation with $\mathrm{HNO}_{3}$ to devulcanize vulcanized rubbers has not yet been studied.

In this work a detailed investigation of the reaction of SBR (Styrene butadiene Rubber) with concentrated nitric acid was carried out. This process is proposed as a novel devulcanization route which shows several advantages such as the use of an available and relatively low cost oxidant, the use of water as solvent, mild reaction conditions and high efficiency.

\section{Experimental}

The experiments were performed with pure vulcanized SBR (Firestone Styrenebutadiene rubber) mechanically grounded to 2-3 $\mathrm{mm}$ particles. The devulcanization reactions were carried out with concentrated $\mathrm{HNO}_{3}(20 \mathrm{~mL}, 63 \%$, 
Merck) and rubber (10 g) in a $100 \mathrm{~mL}$ reflux system with oil bath at $110^{\circ} \mathrm{C}$. After the reaction the polymeric (PF polymeric fraction) and the aqueous phases (WSF water soluble fraction) were separated by simple vacuum filtration using a sintered filter. The polymeric material was extensively washed with distilled water until the cleansing water had neutral $\mathrm{pH}(\mathrm{ca} .1 \mathrm{~L})$ and dried under vacuum at $80^{\circ} \mathrm{C}$ for $4 \mathrm{~h}$. The aqueous phase was evaporated and dried under vacuum at $80{ }^{\circ} \mathrm{C}$. To determine the extractable fraction from the PF (polymeric fraction) a $8 \mathrm{~h}$ Soxleht extraction was carried out to produce an extracted fraction $(\mathrm{ExF})$ and an insoluble fraction (IF). Solubility tests were carried out by mixing $5 \mathrm{~g}$ of the ExF material with $2 \mathrm{~mL}$ solvent (THF, toluene, $\mathrm{CH}_{2} \mathrm{Cl}_{2}$, ethanol, acetonitrile, ethyl acetate) under low energy sonication for $1 \mathrm{~h}$ at $25^{\circ} \mathrm{C}$. After $12 \mathrm{~h}$ equilibrium, $1 \mathrm{~mL}$ of the solution was collected with a volumetric pipette, the solvent evaporated at $80^{\circ} \mathrm{C}$ under vacuum and the solubilized polymer measured by weight. IR spectra were obtained in a Perkin Elmer 283B Instrument in $\mathrm{KBr}$ or in solution. Elemental analyses were carried out in a Perkin Elmer PE2400 CHN. The GPC data was obtained in a Shimadzu LC-10AD equipped with a UV detector SPD-10AV at 254 nm and columns GPC805 and GPC804 with THF or DMF. NMR analyses were carried out with $\mathrm{CDCl}_{3}$ or $\mathrm{D}_{2} \mathrm{O}$ in a Brucker DRX200. TG analyzes were made in SHIMADZU TG $50 \mathrm{H}$ equipment $\left(10{ }^{\circ} \mathrm{C} \mathrm{min}^{-1}\right.$ and air $\left.100 \mathrm{~mL} \mathrm{~min}^{-1}\right)$. TPD-MS (Temperature Programmed Decomposition Mass Spectrometer) analyses were performed by heating the sample at $5^{\circ} \mathrm{C} \mathrm{min}{ }^{-1}$ in a He flow $\left(30 \mathrm{~mL} \mathrm{~min}^{-1}\right)$. A capillary empty silica column near the sample was used to collect and continuously analyzing the decomposition products by a HP 5989A II mass spectrometer.

\section{Results and Discussion}

The oxidative devulcanization process of SBR was carried out with concentrated $\mathrm{HNO}_{3}$ under reflux for 0.5 $10 \mathrm{~h}$. From these treatments three fractions were obtained: (i) a polymeric material insoluble in water (PF), (ii) a water soluble (WSF) and (iii) a volatile fraction (VF) lost during the treatment (Scheme 1).

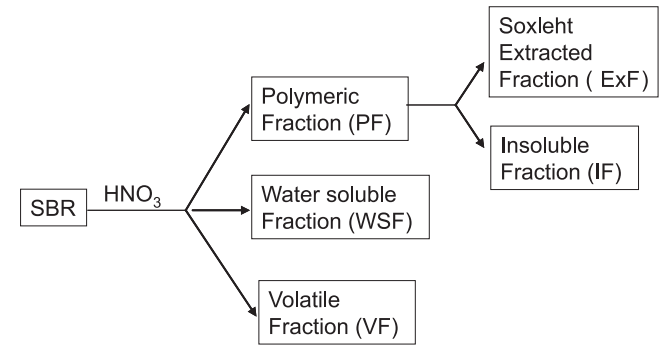

Scheme 1.
The mass balances for the PF, WSF and VF obtained after different treatments are shown in Table 1.

Table 1. Mass balances for the polymeric (PF), water soluble (WSF) and volatile (VF) fractions obtained by different treatments with $\mathrm{HNO}_{3}$

\begin{tabular}{cccc}
\hline Treatment & PF $(w t \%)^{\mathrm{a}}$ & WSF $(w t \%)^{\mathrm{a}}$ & $\mathrm{VF}(\mathrm{wt} \%)^{\mathrm{b}}$ \\
\hline $1 \mathrm{~h} /$ reflux & 83 & 5 & 12 \\
$2 \mathrm{~h} /$ reflux & 65 & 10 & 25 \\
$4 \mathrm{~h} /$ reflux & 64 & 10 & 26 \\
6 h/reflux & 63 & 11 & 26 \\
10 h/reflux & 62 & 10 & 28 \\
\hline
\end{tabular}

abtained after drying all the materials at $80{ }^{\circ} \mathrm{C}$ under vacuum for $4 \mathrm{~h}$ bestimated by weight loss, i.e. the difference VF=100-PF-WSF.

It can be observed that upon reflux with concentrated $\mathrm{HNO}_{3}$ for $1 \mathrm{~h}, 12 \%$ of the material is lost as VF, whereas $5 \%$ is transformed to a WSF and $83 \%$ remain as a solid polymeric fraction (PF). As the reflux time increases to $10 \mathrm{~h}$ the PF fraction is reduced to $62 \%$, strongly favoring formation of volatile compounds (25-28\%).

Treatment with $\mathrm{HNO}_{3}$ strongly modified the physical aspect of the original vulcanized rubber producing in some cases oils and waxes. The solubility of the obtained PF was studied in different solvents such as THF, toluene, hexane, $\mathrm{CCl}_{4}$, ethanol and acetonitrile. Two different fractions were obtained: $(i)$ a soluble devulcanized polymer (extracted by Soxleht, ExF) and (ii) an insoluble fraction (IF) in organic solvents. The \%ExF obtained with THF are shown in Figure 1.

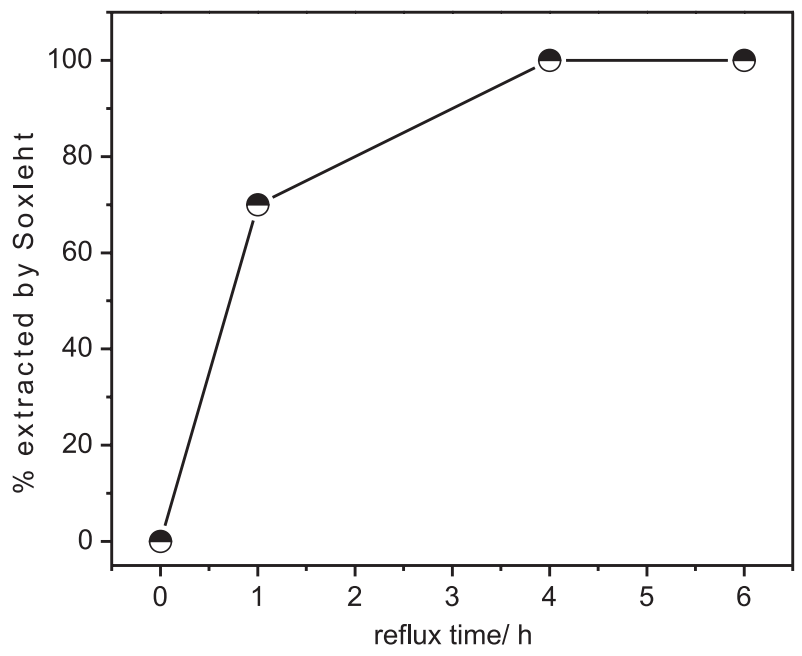

Figure 1. THF Soxleht extraction percentage of the PF obtained by reflux with $\mathrm{HNO}_{3}$ after different periods of time.

It can be observed that nearly no extraction by THF was observed for the original SBR not treated with $\mathrm{HNO}_{3}$. Upon treatment with $\mathrm{HNO}_{3}$ for $1 \mathrm{~h}$ under reflux, however approximately $70 \%$ of the polymeric fraction is soluble in THF. This result clearly indicates a devulcanization process, 
breaking the sulfur crosslinks and producing free soluble polymer chains. The SBR treated under reflux with $\mathrm{HNO}_{3}$ for 4 and $6 \mathrm{~h}$ resulted in a material completely soluble in THF, suggesting complete devulcanization. Soxleht extraction using toluene and hexane showed similar results.

The solubility of the extracted fractions was determined in different solvents and the results are shown in Figure 2.

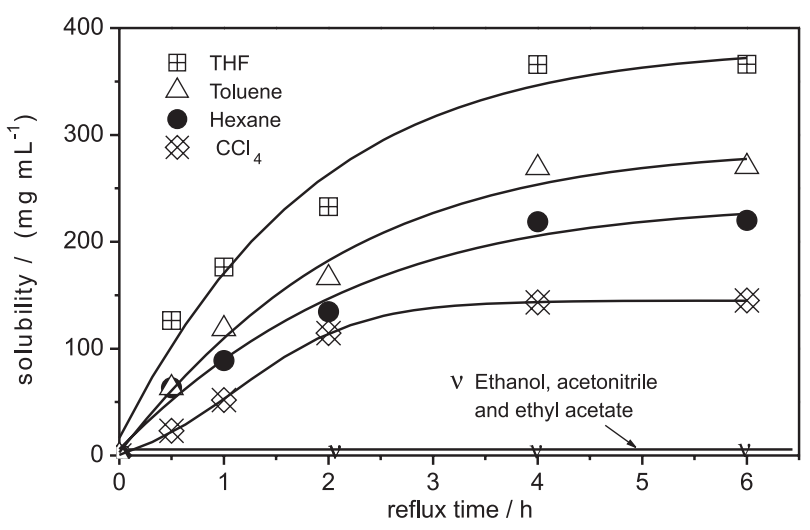

Figure 2. Solubility of the extracted fractions in different solvents.

It can be observed that the extracted fraction shows higher solubility in THF and that the solubility increases for longer reflux time. For less polar solvents, i.e. toluene, hexane and $\mathrm{CCl}_{4}$, the solubility tends to decrease. On the other hand, the material was almost insoluble in more polar solvents such as ethanol, acetonitrile and ethyl acetate.

In order to characterize the extracted polymeric fraction (ExF), CHN elemental analyses, IR, NMR, TG and GPC analyses were carried out. The elemental analyses results are displayed in Table 2.

Table 2. CHN elemental analysis for the extracted polymeric fractions (ExF)

\begin{tabular}{lcccc}
\hline Treatment & $\mathrm{C}(\%)$ & $\mathrm{H}(\%)$ & $\mathrm{N}(\%)$ & others $(\%)$ \\
\hline SBR original & 85.4 & 9.5 & 0.3 & 4.8 \\
$2 \mathrm{~h} /$ reflux & 81.5 & 9.9 & 1.0 & 7.6 \\
$6 \mathrm{~h} /$ reflux & 79.6 & 9.1 & 1.8 & 9.5 \\
$10 \mathrm{~h} /$ reflux & 77.5 & 9.2 & 2.9 & 10.4 \\
\hline
\end{tabular}

It can be observed that the carbon content of $c a .85 \%$ for the original SBR decreased to $c a$. $78 \%$ after reflux for $10 \mathrm{~h}$. It is interesting to observe that the percentage of $\mathrm{N}$ and others strongly increased upon reflux with $\mathrm{HNO}_{3}$ which could be related to oxidation and nitration reactions taking place during the devulcanization process.

Infrared spectroscopic analyses clearly show the presence of new absorptions after treatment with $\mathrm{HNO}_{3}$ (Figure 3).

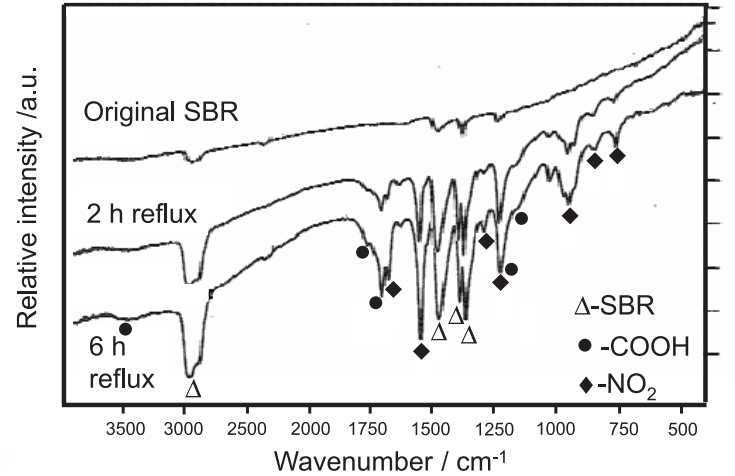

Figure 3. IR spectra of the extracted fractions $(\mathrm{ExF})$ of the SBR refluxed with $\mathrm{HNO}_{3}$ for 2 and $6 \mathrm{~h}$.

The IR spectrum of the original SBR shows weak characteristic absorptions for C-H (ca. 3000, 1300-1480 $\left.\mathrm{cm}^{-1}\right)$ and $\mathrm{CH}_{2}\left(1450-1475 \mathrm{~cm}^{-1}\right)$. On the other hand, the spectra of the $\mathrm{HNO}_{3}$ treated samples show new absorption bands at $1650,1550 \mathrm{~cm}^{-1}$ related to $\mathrm{NO}_{2}$ groups and at $\mathrm{ca}$. $1700-1770 \mathrm{~cm}^{-1}, 1400,1250 \mathrm{~cm}^{-1}$ and $3400 \mathrm{~cm}^{-1}$ likely related to the presence of $\mathrm{C}=\mathrm{O}, \mathrm{C}-\mathrm{O}$ and $\mathrm{OH}$ groups, suggesting the formation of carboxylic acid, $\mathrm{COOH}$. It was clearly observed for longer treatment times with $\mathrm{HNO}_{3}$ that the intensity of $\mathrm{NO}_{2}$ and $\mathrm{COOH}$ bands also increased.

TPD/MS (Temperature Programmed DecompositionMass Spectrometry) experiments were carried out to identify possible functional groups present in the devulcanized material. Figure 4 clearly shows the signals at $\mathrm{m} / \mathrm{z}, 44$ and 46 which are likely related to $\mathrm{CO}_{2}$ and $\mathrm{NO}_{2}$, respectively, formed from the decomposition of $-\mathrm{COOH}$ and $-\mathrm{NO}_{2}$ groups in the material.

No $m / z$ signal 64 or 80 related to $\mathrm{SO}_{2}$ or $\mathrm{SO}_{3}$ was detected, suggesting that probably most of the sulfur content was removed from the polymeric fraction.

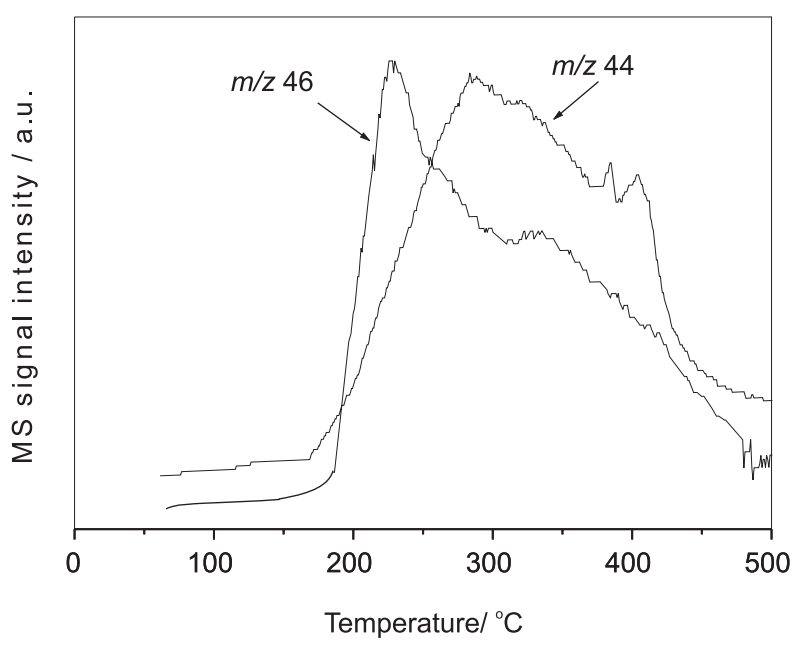

Figure 4. TPD-MS (Temperature Programmed Decomposition- Mass Spectrometry) of the material produced by refluxing SBR with $\mathrm{HNO}_{3}$ for $6 \mathrm{~h}$. 
Analyses by ${ }^{1} \mathrm{H}$ NMR showed the presence of signals related to protons bound to aromatic rings $(\delta 7.0-8.0)$ and oxygen $(\delta 4.0-4.5) .{ }^{13} \mathrm{C}$ NMR analysis showed the presence of signals at $\delta 132.6,130.9$ and 128.8 related to the aromatic carbons, and $\delta 38.7$ and 59.5 related to aliphatic carbons. New signals were also observed at $\delta 167.7$ likely related to $\mathrm{COOH}$ carbons, and at $\delta 68.1$, probably due to carbons bound to $-\mathrm{NO}_{2}$ groups.

Thermogravimetric analyses of the SBR sample and the PF obtained by treatment with $\mathrm{HNO}_{3}$ for $4-6 \mathrm{~h}$ and 10h under reflux are shown in Figure 5.

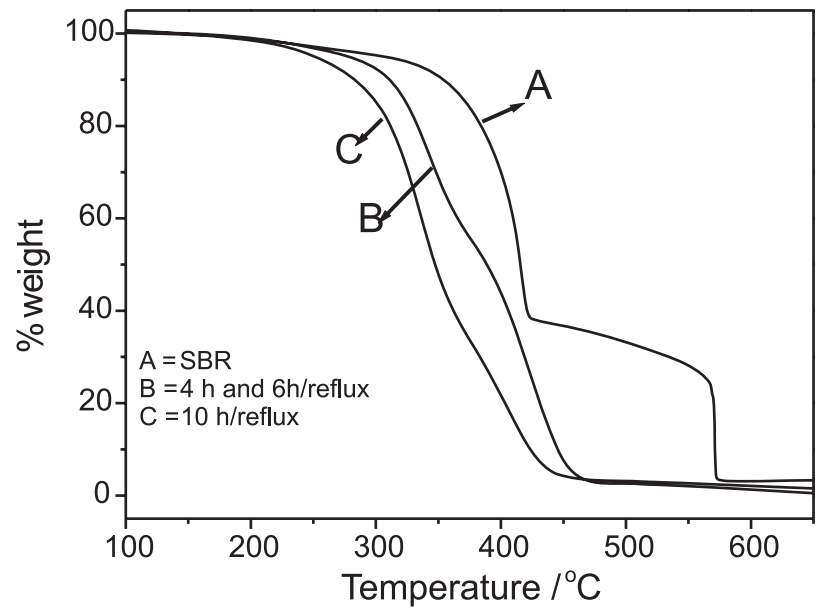

Figure 5. Thermogravimetric analyses (in air atmosphere) of the original SBR and the PF obtained by reflux with $\mathrm{HNO}_{3}$ for 4-6 and $10 \mathrm{~h}$

The original SBR showed a typical TG with two weight losses at $350-450{ }^{\circ} \mathrm{C}$ and $560-580{ }^{\circ} \mathrm{C}$, the first one related to the SBR polymer decomposition and the second one due to the carbon black oxidation..$^{22}$ It can be observed that as the SBR is treated with $\mathrm{HNO}_{3}$ the on set decomposition temperatures are strongly decreased. The weight loss at lower temperature is related to thermal decomposition of $-\mathrm{COOH}$ and $-\mathrm{NO}_{2}$ groups, ${ }^{23}$ followed by the decomposition of the polymeric fraction. Also, the weight loss due to the carbon black oxidation by air completely disappears after treatment of the SBR with $\mathrm{HNO}_{3}$. This result suggests that the carbon black in the rubber is strongly attacked under the reaction conditions. Literature work ${ }^{24}$ showed that carbon black can be easily oxidized by concentrated nitric acid to produce water soluble polyaromatic compounds. Therefore, these results suggest that treatment of the $\mathrm{SBR}$ with $\mathrm{HNO}_{3}$ leads to the oxidation, not only of the polymeric material, but also of the carbon black, to produce a water soluble material. These water soluble compounds from the carbon black are removed during extensive washing of the PF.

GPC (Gel Permeation Chromatography) analyses of the extracted fraction (ExF) of the devulcanized SBR showed chromatograms which are strongly dependent on the reflux time with $\mathrm{HNO}_{3}$ (Figure 6).

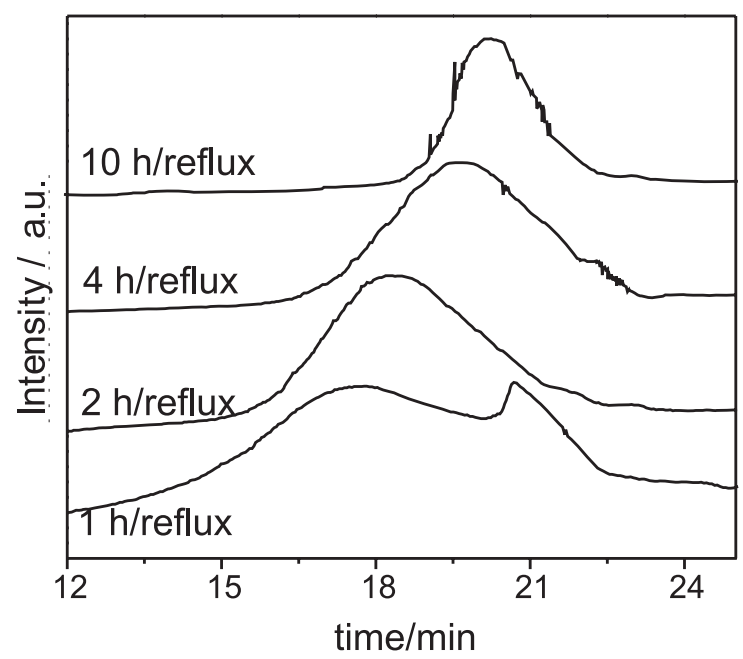

Figure 6. GPC analyses of the extracted fractions (ExF) of SBR devulcanized under reflux with $\mathrm{HNO}_{3}$.

After refluxing with $\mathrm{HNO}_{3}$ for $1 \mathrm{~h}$, a broad GPC peak centered at shorter retention times is observed suggesting a wide molecular weight distribution around the average MW molecular weight of $c a$. 27700. It is also observed the presence of another peak centered near 21 min which is likely due to a polymeric fraction with small MW. For the samples obtained by treatment for 2, 4 and $10 \mathrm{~h}$ two effects are observed: ( $i$ ) a narrowing of the MW distribution and (ii) a decrease in the average molecular weight to 23500, 16500, 6500 and $4500 \mathrm{Da}$, respectively. These results suggest that the reaction with $\mathrm{HNO}_{3}$ is not only oxidizing the sulfide crosslinks, leading to devulcanization, but is also cleaving the polymer carbon chains decreasing the MW.

The water soluble fraction (WSF) was obtained as a highly hygroscopic oil. The GPC analyses for all the obtained WSF showed similar peaks near 22 min corresponding to a small average molecular weight of $c a$. 1000-1500 Da.

The CHN elemental analyses for the WSF results, shown in Table 3, showed low carbon, hydrogen and nitrogen contents, suggesting the presence of large amounts of oxygen and other elements.

IR analyses (not shown) of the WSF showed very strong absorptions at 1600 and $1340 \mathrm{~cm}^{-1}\left(\mathrm{C}-\mathrm{NO}_{2}\right)$ and 3450 and

Table 3. CHN elemental analyses of the water soluble fractions

\begin{tabular}{lcccc}
\hline Treatment & $\mathrm{C}(\%)$ & $\mathrm{H}(\%)$ & $\mathrm{N}(\%)$ & others (\%) \\
\hline $2 \mathrm{~h} /$ reflux & 16.0 & 1.2 & 1.9 & 80.9 \\
$1 \mathrm{~h} /$ reflux & 17.9 & 3.2 & 0.6 & 78.3 \\
$10 \mathrm{~h}$ /reflux & 19.9 & 2.3 & 0.5 & 77.3 \\
\hline
\end{tabular}


$1750 \mathrm{~cm}^{-1}(\mathrm{COOH})$ indicating a high degree of nitration and oxidation of the polymer. The TPD/MS experiments with the WSF showed strong signals with $m / z, 44$ and 46 in the $100-300{ }^{\circ} \mathrm{C}$ temperature range, likely related to the decomposition of the carboxylic $(-\mathrm{COOH})$ and nitro groups $\left(-\mathrm{NO}_{2}\right)$. The signal at $m / z 64$ was also detected in the temperature ranges of $200-350$ and $450-550{ }^{\circ} \mathrm{C}$, and is related to $\mathrm{SO}_{2}$, likely formed by the decomposition of oxidized sulfur groups such as $-\mathrm{SO}_{3}^{-}$and $\mathrm{SO}_{4}{ }^{2-}$ (Figure 7).

This WSF is likely formed by compounds originated from two sources: $(i)$ the severe oxidation of the SBR polymer to produce highly oxidized small MW polar molecules and (ii) water soluble polyaromatic compounds produced by the oxidation of the carbon black.

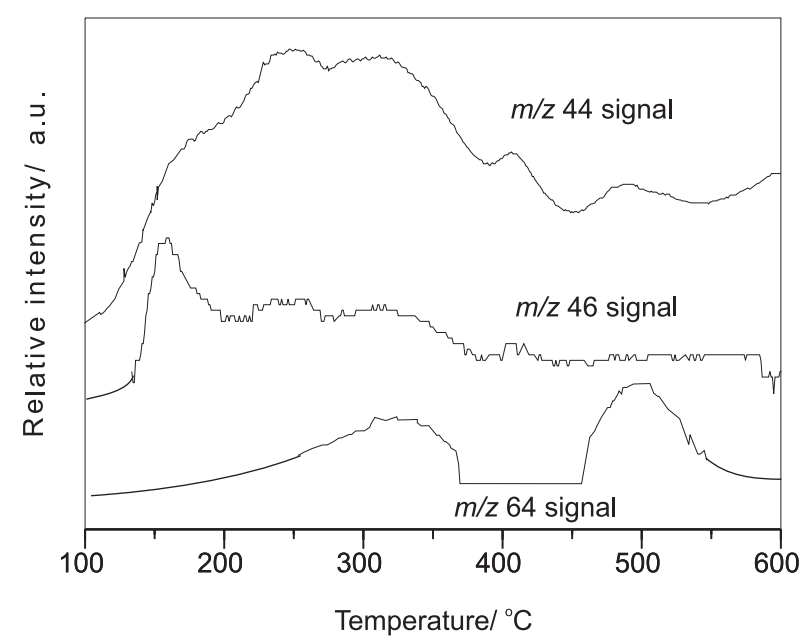

Figure 7. TPD-MS of the WSF obtained from the reaction of SBR with $\mathrm{HNO}_{3}$ under reflux for $6 \mathrm{~h}$.

\section{Reaction mechanism}

It is well known that concentrated nitric acid is a strong oxidizing agent and can oxidize disulfide bonds ${ }^{19}$ according to the process shown in Equation 1.

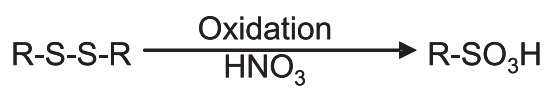

Under more aggressive conditions, the sulfonic group can be further oxidized and released to the aqueous solution as sulfate (Equation 2):

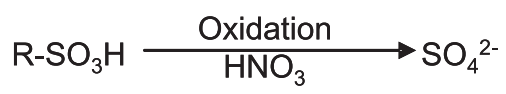

In fact, addition of a barium nitrate to the aqueous solution after treatment showed formation of a white precipitate $\left(\mathrm{BaSO}_{4}\right)$, indicating the presence of sulfate. Therefore, one can consider that the devulcanization process takes place by oxidation of the sulfur crosslinks with $\mathrm{HNO}_{3}$, producing free polymer chains. This devulcanized polymer is soluble in different organic solvents. On the other hand, the concentrated nitric acid can also react with the polymer carbon backbone by two pathways: (i) nitration and (ii) oxidation. Nitration of styrene polymers with $\mathrm{HNO}_{3}$ is a well known process ${ }^{25,} 26$ and probably takes place at the aromatic ring according to equation 3 :

Polymer-Ph $\longrightarrow \mathrm{HNO}_{3} \longrightarrow$ Polymer-Ph-NO

These $-\mathrm{NO}_{2}$ groups have been clearly identified by IR spectroscopic analyses and TPD-MS experiments, which are in agreement with the increase in the $\mathrm{N}$ content observed in the elemental analyses. The polymer can also be oxidized by $\mathrm{HNO}_{3}$ to produce oxygenated groups such as $-\mathrm{OH}$ and $-\mathrm{COOH}$, as detected by IR and NMR spectroscopies and TPD-MS experiments. The $\mathrm{HNO}_{3}$ oxidation of carbonaceous materials is also well described in the literature. ${ }^{24}$ Although, the mechanism and the location of these oxygenated groups are not clear, one can envisage that the oxidation might take place at different places in the carbon styrene butadiene polymer such as: the aromatic ring and at secondary or tertiary carbon of the main chain. In the case of oxidation at the aliphatic carbons the main polymeric chain will be broken, leading to the decrease of the polymer molecular weight. This effect was observed in the GPC measurements, which showed that the molecular weight decreases as the treatment with $\mathrm{HNO}_{3}$ was carried out at longer times. The polymer chain severe oxidation and fragmentation is responsible for the water soluble organic fraction. This fraction is probably composed of polar highly oxygenated molecules with average molecular weight lower than 1500 with a low carbon content of $16-20 \%$. Some important issues which must be considered for the technical and economical viability of this process are: $(i)$ the recycling of the remaining $\mathrm{HNO}_{3}$ after devulcanization, (ii) the treatment of the aqueous and gaseous effluents produced during the process and (iii) the unique properties of the devulcanized material.

The devulcanization process with $\mathrm{HNO}_{3}$ even under optimized conditions will produce an aqueous phase which is strongly acidic. Preliminary studies suggested that by simple distillation 5 to $10 \%$ of the initial nitric acid can be recovered from this aqueous phase. This aqueous phase contains a high concentration of organic matter, sulfate and different metals, especially zinc, which will demand treatment for suitable disposal. Also during the reaction significant amount of $\mathrm{NO}_{2}$ gas is formed as a by-product of the oxidation process and also from the decomposition 
of $\mathrm{HNO}_{3}$, requiring a suitable treatment. Finally, an interesting point to consider is that the oxidative devulcanization with $\mathrm{HNO}_{3}$ produces a devulcanized polymer with unique characteristics. This polymeric material contains oxygenated functional groups in a wide range of concentrations which confere to the material completely novel and interesting properties. Although more detailed investigations are necessary, several potencial applications of this material can be envisage, such as special adhesives, fillers, production of polymer blends, etc.

\section{Conclusions}

This novel oxidative process shows great potential for the devulcanization of waste tires using solely $\mathrm{HNO}_{3}$, which is an available low cost oxidant. The reaction takes place initially by oxidation of the sulfur crosslinks. However, two competitive reactions also occur, i.e. nitration and oxidation to form $-\mathrm{NO}_{2}$ and $-\mathrm{COOH}$ groups. Under more aggressive conditions severe oxidation with fragmentation of the polymer chain to form water-soluble highly oxidized low molecular weight species also occurs.

\section{Acknowledgments}

The authors are grateful for financial support from FAPEMIG, PRPq-UFMG, SEBRAE-MCT, CNPq and Instituto Inovação.

\section{References}

1. Adhikari, B.; De, D.; Maiti, S.; Prog. Polym. Sci. 2000, 25, 909.

2. Cotton, F.H.; Gibbons, P.A.; US pat. 2,408,296 1946.

3. Cotton, F.H.; Gibbons, P.A.; US pat. 2,471,866 1949.

4. Cotton, F.H.; Gibbons, P.A.; US pat. 2,469,529 1949.

5. Webb, F.J.; Cooks, W.S.; Albert, H.E.; Smith, G.E.P.; Ind. Eng. Chem. 1954, 46, 1711.

6. Tewksbury, L.B.; Howland, L.H.; Can. pat. 215,952 1948.

7. Hunt, L.K.; Kovalak, R.R.; US pat. 5,891,926A 1999.

8. Moore, C.G.; Trego, B.R.; J. Appl. Polym. Sci. 1964, 8, 1957.

9. Moore, C.G.; Trego, B.R.; J. Appl. Polym. Sci. 1961, 5, 299.
10. Saville, B.; Watson, A.A.; Rubber Chem. Technol. 1967, 40, 210.

11. Campbell, D.S.; Rubber Chem. Technol. 1967, 40, 100.

12. Parks, C.R.; Chapman, D.K.; Cox, W.L.; Rubber Chem. Technol. 1970, 43, 572.

13. Onouchi, Y.; Inagaki, S.; Okamoto H.; Furukawa, Y., J. Am. Chem. Soc., Div. Polym. Prep. 1979, $20,943$.

14. Kawabata, N.; Yamashita, S.; Furukawa, Y.; Bull. Chem. Soc. Jpn. 1978, 51, 62; Kawabata, N.; Yamashita, S.; Furukawa, Y.; J. Appl. Polym. Sci. 1977, 21, 2201.

15. Kawabata, N.; Yamashita, S.; Furukawa, Y.; J. Appl. Polym. Sci. 1981, 26, 1417; Kawabata, N.; Yamashita, S.; Furukawa, Y.; Nippon Gomu Kyokaishi 1979, 52, 764.

16. Straube, G.; Straube, E.; Newmann, W.; Ruckalf, H.; Forkmann, R.; Loffler, M.; US pat. 5,275,948 1994.

17. Kawabata, N.; Yamashita, S.; Akita, K.; Nippon Gomu Kyokaishi 1976, 49, 844; Kim, J.K.; Park, J.W.; J. Appl. Polym. Sci. 1999, 72, 1453; Newman, W.; German pat. 4,042,009 1992; Loffler, M.; Deutsche Kautschuk Tagung 1994, 1.

18. Tsuchii, A.; Suzuki, T.; Takeda, K.; Appl. Environ. Microbiol. 1985, 50, 965.

19. Savige, S.; Maclaren, K.; Organic Sulfur Compounds, Vol. 2, Pergamon Press: New York, 1996, pp. 367; Capozzi, C.; Modena, S.; The Chemistry of the Thiol Group, Wiley: New York, 1974, pp. 785.

20. Akhtar, S.; Setua, D.K.; De, P.P.; De, S.K.; Polym. Degrad. Stab. 1985, 10, 299.

21. Yehia , A.A.; Mull, M.A.; Ismail, M.N.; Hefny, Y.A.; AbdelBary, E.M.; J. Appl. Polym. Sci. 2004, 93, 30.

22. Williams, P.T.; Besler, S.; Fuel 1995, 74, 1277.

23. Rios, R.R.V.A.; Alves, D.E.; Dalmázio, I.; Bento, S.F.V.; Donnici, C.L.; Lago, R.M.; Mat. Res. 2003, 6, 129; Lisovskii, A.; Semiat, R.; Aharoni, C.; Carbon 1997, 35, 1639; Lisovskii, A.; Semiat, R.; Shter, G.E.; Aharoni, C.; Carbon 1997, 35, 1645.

24. Kamegawa, K.; Nishikubo, K.; Kodama, M.; Adachi, Y.; Yoshida, H.; J. Colloid Interface Sci. 2003, 268, 58; Kamegawa, K.; Nishikubo, K.; Kodama, M.; Adachi, Y.; Yoshida, H.; Carbon 2002, 40, 1447; Kamegawa, K.; Nishikubo, K.; Yoshida, H.; Carbon 1998, 36, 433.

25. Philippides , A.; Budd, P.M.; Price, C.; Cuncliffe, A.V.; Polymer 1993, 34, 3509.

26. Karaivanova, M.S.; Georgiev, T.K.; Oxid. Commun. 2003, 275. 